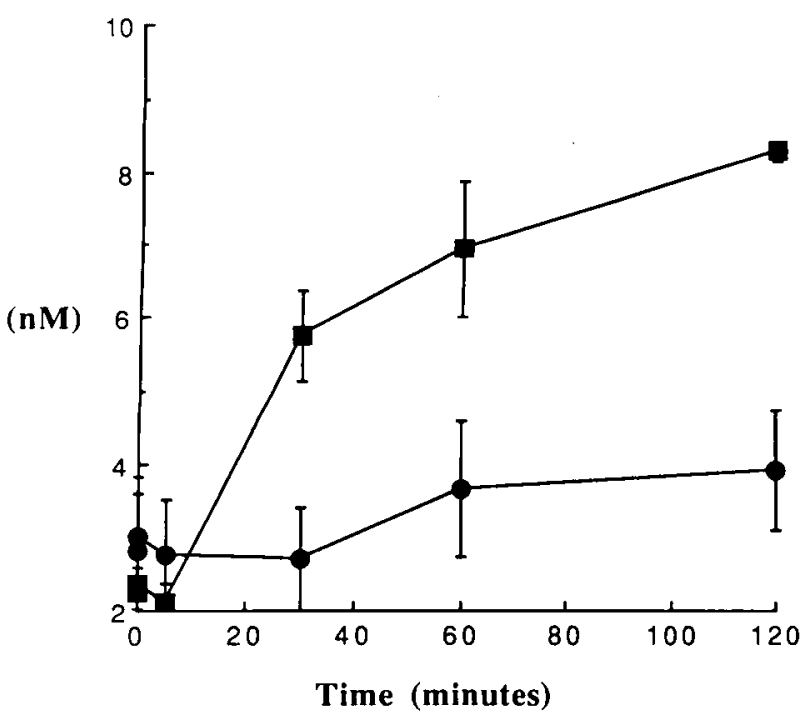

Fig. 2. Plasma F1.2 concentrations (mean \pm standard error of the mean) for heparin $(n=5)$ and r-hirudin $(1.07 \mu \mathrm{mol} / \mathrm{L}$, $n=5$ ). Stored plasma was not available to measure $\mathrm{F} 1.2$ in five heparin samples and in r-hirudin $(3.0 \mu \mathrm{mol})$ samples.

underscores the massive thrombotic stimulus produced by blood circulation through extracorporeal perfusion systems that contain an oxygenator. Lindhout, Blezer, and Hemker ${ }^{8}$ previously found that the reaction between thrombin and $r$-hirudin does not prevent trace amounts of thrombin produced via the extrinsic pathway. In dogs, Walenga and associates ${ }^{9}$ observed more fibrin formation during 60 minutes of cardiopulmonary bypass with r-hirudin anticoagulation than with a reduced dose of heparin.

The difference between heparin and r-hirudin in suppressing FPA formation is not explained by reaction speed. Both drugs bind thrombin very rapidly. The second/order rate constant for native hirudin with thrombin ${ }^{3}$ is $3.25 \times 10^{7} \mathrm{~mol} / \mathrm{L}^{-1} \mathrm{sec}^{-1}$ and for antithrombin III with thrombin in the presence of heparin, ${ }^{10}$ $3.7 \times 10^{7} \mathrm{~mol} / \mathrm{L}^{-1} \mathrm{sec}^{-1}$. The superior inhibitory effect of heparin-catalyzed antithrombin III on thrombin formation is explained by the ability to also inhibit factor Xa. Heparin-antithrombin III complex strongly inhibits thrombin and factor $\mathrm{Xa}$ and weakly inhibits other soluble coagulation proteins ${ }^{11}$; $r$-hirudin only binds thrombin. In this system, F1.2, which is produced when prothrombin is cleaved to form thrombin by factor $\mathrm{Xa}$, increases in the presence of $\mathrm{r}$-hirudin but not with heparin. Heparin, therefore, remains the best anticoagulant for cardiopulmonary bypass.

A. Bernabei, $M D$

A. K. Rao, $M D$

S. Niewiarowski, $M D, P h D$

R. W. Colman, $M D$

L. Sun, $M D$

L. H. Edmunds, Jr., MD

Department of Surgery

School of Medicine

University of Pennsylvania

Sol Sherry Thrombosis Research Center

Hematology Division

Departments of Medicine and Physiology

Temple University

Philadelphia, PA. 19104

\section{R EFERENCES}

1. Boisclair MD, Lane DA, Philippou H, Sheikh S, Hunt B. Thrombin production, inactivation and expression during open heart surgery measured by assays for activation fragments including a new ELISA for prothrombin Fragment F1 + 2. Thromb Haemost 1993;70:253-8.

2. Brister SJ, Ofosu FA, Buchanan MR. Thrombin generation during cardiac surgery: Is heparin the ideal anticoagulant? Thromb Haemost 1993;70:259-62.

3. Stone SR, Hofsteenge J. Kinetics of the inhibition of thrombin by hirudin. Biochem 1986;25:4622-8.

4. Talbot M. Biology of recombinant hirudin (CGP 39393): a new prospect in the treatment of thrombosis. Sem Thromb Hemost 1989; 15:293-301.

5. Marki WE, Wallis RB. The anticoagulant and antithrombotic properties of hirudins. Thromb Haemost 1990; 61:344-8.

6. Wachtfogel Y, Kucich U, Hack CE, Niewarowski S, Colman RW, Edmunds LH Jr. Aprotinin inhibits the contact, neutrophil, and platelet activation systems during simulated extracorporal perfusion. J THORAC CARDIOVASC SURG 1993;106:1-10.

7. Zoldhelyi P, Webster MWI, Fuster V, et al. Recombinant hirudin in patients with chronic stable coronary artery disease. Circulation 1993;88:2015-22.

8. Lindhout T, Blezer R, Hemker HC. The anticoagulant mechanism of action of recombinant hirudin (CGP 39393) in plasma. Thromb Haemost 1990;64:464-8.

9. Walenga JM, Bakhos M, Messmore HL, Fareed J, Pifarré R. Potential use of recombinant hirudin as an anticoagulant in a cardiopulmonary bypass model. Ann Thorac Surg 1991;51:271-7.

10. Olson ST, Bjork I. Predominant contribution of surface approximation to the mechanism of heparin acceleration of the antithrombin-thrombin reaction. J Biol Chem 1991; 266:6353-62.

11. Rosenberg RD, Bauer KA. The heparin-antithrombin system: a natural anticoagulant mechanism. In: Colman RW, Hirsh J, Marder VJ, Salzman EW. Hemostasis and thrombosis, basic principles and clinical practice. R.W. Colman, J. Philadelphia: JB Lippincott, 1994:837-60.

\section{Effects of storage with University of Wisconsin solution on human saphenous vein endothelium}

\section{To the Editor:}

In cardiac surgery the importance of preserving the endothelial lining, especially during coronary artery bypass graft procedures, is widely known. ${ }^{1,2}$

In a recent report Drs. Mankad, Slavik, and Yacoub ${ }^{3}$ presented a new and interesting investigation concerning the effects of University of Wisconsin solution (UWS) at differentes temperatures on endothelial function. The authors showed that hypothermic UWS best preserves the functional integrity of the endothelium.

Such a solution has also been used by others, ${ }^{4}$ at room temperature and in comparisons with other solutions, for storage of the baboon saphenous vein. On the basis of responses to 
contractile or relaxant agents and of reports on histologic changes, the authors demonstrated that UWS and physiologic salt solution (PSS) are the best options for storage of saphenous vein.

We recently investigated the effect of UWS and other bathing media on morphologic features of the human saphenous vein endothelium by means of an electron microscopic comparative analysis. Furthermore, we evaluated contractile activity of human saphenous vein specimens at different bathing durations. All patients in the study had given their informed written consent.

Distal segments of human saphenous vein were harvested for microscopic evaluation by a "no-touch" technique from eight patients who had undergone bypass grafting. Each segment was divided into seven specimens after a low-pressure distention $(120 \mathrm{~mm} \mathrm{Hg}$ ) with PSS at room temperature. The first of the segments was fixed with $2.5 \%$ glutaraldehyde solution, immediately after being harvested, for basal evaluation; three were fixed after 30 minutes, and three after being bathed for 5 hours at $4^{\circ} \mathrm{C}$ in autologous, oxygenated, heparinized blood (AOHB); heparinized PSS with added papaverine $(0.4 \mathrm{gm} / \mathrm{ml}$ ) (HPSS); or UWS. To evaluate contractile activity of the human saphenous vein, we used $3 \mathrm{~cm}$ long segments harvested with the same technique from 12 other patients. Each venous segment, once cleaned of the adherent connective tissue, was then cut into three ring-shaped specimens that were preserved with the same solutions for 30 minutes, 5 hours, and 24 hours. We repeated this procedure four times with each solution. After each bathing period was ended the specimens were superfused in a tissue organ bath at a rate of $2.5 \mathrm{ml} / \mathrm{min}$ with Krebs solution at $37^{\circ}$ C. The solution was gassed with $95 \%$ oxygen and $5 \%$ carbon dioxide. A contractile response was then provoked with a 30 $\mathrm{mmol} / \mathrm{L}$ dose of potassium chloride and was recorded with auxotonic transducers at a resting tension of $2 \mathrm{gm}$ after a 30-minute period of equilibration.

At microscopic evaluation the control specimens had the best preserved endothelium that one could expect. AOHB appeared to be the least adequate solution for preservation: endothelial cell loss and detachment were already evident after a 30-minutes bathing period. Specimens stored in HSSP and UWS had a well-preserved and comparable structure after 30 minutes' bathing even if a major degree of alteration was evident with HSSP (presence of intracellular edema). After 5 hours' of bathing all specimens stored in AOHB and HSSP showed complete endothelial necrosis, whereas specimens stored in UWS were better preserved (only subendothelial edema and abnormal mitochondria).

Contractile response was present at any bathing time in AOHB and UWS specimens; on the contrary, specimens preserved with HSSP were viable only after 30 minutes (100\% of cases) and after 5 hours (50\% of cases) of bathing.

In conclusion, our data suggest that UWS, considered effective in maintaining endothelial function in the isolated rat heart as well as in isolated baboon saphenous vein, can also be considered a suitable storage solution for human saphenous vein. Even though UWS was as effective as AOHB in provoking contractile response of the human saphenous vein, this study really shows that UWS better preserves endothelial structure after a prolonged storage. Nevertheless, we think that further studies are necessary, because of the multitude of factors that can affect endothelium (i.e., harvesting techniques, ischemia timing, pressure distention, irrigation solutions, and storage temperature), to confirm the superiority of UWS in preventing endothelial damage and to identify it as the ideal bathing medium for human saphenous vein storage.

Edoardo Santoli, $M D$

Tarcisio Vago, $B D$

Renzo Boldorini, $M D$

Elena Sala, $B D$

Department of Thoracic and Cardiovascular Surgery Hospital "L. Sacco" Milan, Italy

\section{REFERENCES}

1. Catinella FP, Cunningham JN, Srungaram RK, et al. The factors influencing early patency of coronary artery bypass vein grafts. J THORAC CARDIOVASC SURG 1982;83:686-700.

2. Zilla P, von Oppel U, Deutsch M. The endothelium: a key to the future. J Cardiac Surg 1993;8:32-60.

3. Mankad P, Slavik Z, Yacoub M. Endothelial dysfunction caused by University of Wisconsin preservation solution in the rat heart. J THORAC CARDIOVASC SURG 1992;104:161824.

4. Boerboom LE, Wooldridge TA, Olinger GN, Rusch NJ. Effects of storage solutions on contraction and relaxation of isolated saphenous veins. J Cardiovasc Pharmacol 1992;20 (Suppl 12):S80-4.

\section{A new clamp for division and suture of patent ductus arteriosus}

\section{To the Editor}

A new clamp has been developed for the surgery of patent ductus arteriosus (PDA). Its curvature allows more secure biting of the aortic and pulmonary walls, allowing greater safety during division and suture of PDAs, particularly in the case of short, large PDAs.

This new clamp (Codman \& Shurtleff, Inc., Randolph, Mass.) is a modification of the straight ( $\mathrm{CH} \mathrm{6500)}$ or angled (CH 5602) Potts clamp (V. Mueller, McGaw Park, Ill.) widely used for the division and suture of PDAs. ${ }^{l}$ Once the two clamps are located perpendicular to the aorta, they lie nicely on each side of the operative field and the exposure is optimal (Fig. 1). The concave curvature (Fig. 2) of the clamp's end allows a sidebiting of the aorta and the pulmonary artery, rather than just of the PDA itself, allowing adequate tissue for performance of an easy suture after division of the PDA. Like the Potts clamp, the orientation of this clamp allows clamping and suture perpendicular to the direction of the aorta, and this avoids any stenosis at the suture site.

I have used this clamp in several patients in whom the diagnosis was made and the operation done after the age of 6 months. These patients had not been able to benefit from invasive catheter closure. In all cases, the operation was very easy, and I felt more secure than with the classic straight clamps for PDA.

It may seem pretentious to try to improve a technique that in all reports procures excellent results with a negligible morbidity and mortality. In addition, in most occidental and in many other centers the number of patients with PDA referred for surgical treatment is decreasing because of nonsurgical means to close the PDA. ${ }^{2,3}$ However, this nonsurgical technique is not applicable in all cases of PDA. It requires an expertise that is not present in all centers, and its overall cost makes surgery preferable in many countries. Therefore it is likely that, worldwide, 